\title{
CORRESPONDENCE
}

Monitoring adverse reactions to drugs V W M Drury, FRCGP; H W K Acheson, FRCGP $\ldots \ldots \ldots \ldots \ldots \ldots$

Anticonvulsant osteomalacia

C Christiansen, MD, and P R $\phi$ dbro, MD . . . . .439

Misuse of statistical methods

E D West, FRCP; S Senn, BA..........440

Fractures of the tibia

H U Cameron, FRCS(c); R W Griffiths,

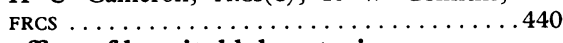

Staffing of hospital laboratories

W A J Crane, FRCPATH, and others.......441

Behaviourism

J Wolpe, мD..............441

Suppressing lactation

K O'Driscoll, FRCOG; R G H Wade, мв....441

Amoxil and Talpen

I W B Grant, FRCPED; E T Knudsen,

FRCPATH ................442

Predicting fetal death

Anne C Davies, and others. . . . . . . . . . .443

Plasma propranolol levels in Crohn's

disease and coeliac disease

B T Cooper, MRCP, and others; R E

Schneider, FRCPED, and C F Hawkins,

FRCP $\ldots \ldots \ldots \ldots \ldots \ldots \ldots \ldots \ldots \ldots 43$
Allergy to diazepam

S K Majumdar, MB; J S Comaish, FRCP... . 444

Atrial fibrillation in the elderly

E B Grogono, fRCGP. . . . . . . . . . . . . . . .444

Progestasert

H McNulty, PHD . . . . . . . . . . . . . 444

Arthroscopy of the knee

S C Gallannaugh, FRCS.............. 445

Carboxyhaemoglobin in lead workers

W R Lee, MD, and H Dhanapala, MB . . . . . . 445

Timing of cervical smears

H C McLaren, FRCOG, and A J Lucas, MB . . . . 445

Radiation-induced breast cancer

D H Patey, FRCS ...............445

Missing tails

J Frampton, frCoG. . . . . . . . . . . 445

Disopyramide in ventricular fibrillation

Tantirimudalige D I M S de Lanerolle, MB . . 446

Tetracycline resistance of group $A$

streptococci from different sites

P A Boswell, MRCPATH, and G E Hillier,

FIMLS ..................446

Possible immunological effect of

oxprenolol

R Nessi, MD
Antibiotic myths

M J Lewis, MD . . . . . . . . . . . . 4446

Access to oral contraceptives

Elizabeth M Elliott, MB..............446

Local gold toxicity

J A N Rennie, MD . . . . . . . . . . . . .446

Lymph-node puncture

P C Srivastava, MD . . . . . . . . . . . . 447

OChemoprophylaxis of malaria

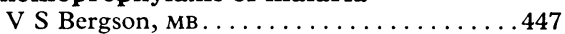

Subclinical hypothyroidism

P B S Fowler, FRCP . . . . . . . . . . . . . 447

Too many doctors and in the wrong

places?

Places?

DHSS maternity leave

Carol M Blandford, fFarcs . . . . . . . 447

GP specialists

J K $M$ Hulbert, MD . . . . . . . . . . . . . . . . 448

Increased NHS pensions for war service

W H Gossip, MRCGP.............. 448

How many tiers?

E P Morley, FRCP. . . . . . . . . . . . . 448

Doctors and pressure groups

R W Beard, FRCOG, and D B Paintin,

FRCOG $\ldots \ldots \ldots \ldots \ldots \ldots \ldots \ldots \ldots 448$
Correspondents are urged to write briefly so that readers may be offered as wide a selection of letters as possible. So many are being received that the omission of some is inevitable. Letters should be signed personally by all their authors.

\section{Monitoring adverse reactions to drugs}

SIR,-The proposal for a scheme of positive monitoring for adverse reactions to drugs described by Professor C T Dollery and Professor M D Rawlins (8 January, p 96) under the heading "For Debate" is remarkable in that so important a topic has stimulated so little response in your correspondence columns. In the past few years we have seen in this country and others at least three major medical disasters relating to thalidomide, practolol, and subacute myelo-optic neuropathy. With the introduction of new chemical entities and new combinations of old entities further disasters may lie around the corner and the effects of this upon innovation by drug companies and patient confidence is potentially very serious.

I believe, personally, that there are several aspects of the scheme proposed by Professors Dollery and Rawlins which are unacceptable. The direct questionnaire to patients would, in my view, introduce major problems in the doctor/patient relationship. Payment for reports seems to me ethically undesirable as well as posing problems of introduction of bias. Nevertheless, these objections and other more minor ones are not arguments against the important principles debated in the article.

There is unlikely to be any single method of monitoring that will entirely eliminate risk. Voluntary reporting, cohort studies of the type described in this article and of other types, and case control studies will all be necessary. What is certain is that the profession and the Department of Health and Social Security should be thinking about the problem as a matter of some urgency.

It is particularly unfortunate that at this very time, and presumably for financial expediency, member States should have chosen this moment to withdraw support from the agency within the World Health Organisation working on this problem. Members of the profession should contact their members of Parliament in the hope that the United Kingdom will not leave Sweden to shoulder the whole burden and will allow the work in Geneva to continue.

University Department of Medicine,

M DRURY Oueen Elizabeth Hospital, Queen Eliza

SIR,-The concept of monitored release for new drugs put forward by Professors $C T$ Dollery and M D Rawlins (8 January, p 96) is worthy of support and could be implemented relatively easily. Once marketed, new drugs are prescribed by general practitioners on Form FP/EC 10, which contains a record of the name and address of the patient and the prescriber. Even when the prescription of newly marketed drugs is initiated by hospital medical staff it is often continued by GPs. Such prescriptions could be sent to the Committee on Safety of Medicines by prescription pricing bureaux. Subsequently the committee could address an inquiry to the prescriber, if necessary at intervals, requesting information about unexpected effects, other drugs prescribed concurrently, and the patient's subsequent history. Remuneration could be at the same rate as for a medical report to the regional medical officer of the Department of Health and Social Security.

If this proposal were to be adopted in parallel with the current voluntary "yellowcard" notification system adverse effects might be identified much earlier than at present.

H W K ACHESON

University Department of General

Practice,

Darbishire
Manchester

\section{Anticonvulsant osteomalacia}

SIR,-In 1972 an authoritative British journal stated editorially that "though [anticonvulsant osteomalacia] may be only at a biochemical level, sound medical practice is to offer prophylactic vitamin therapy before frank bone disease develops." To us your recent leading article (4 December, $p$ 1340), based on the accumulated evidence of the past four years, takes a more balanced view concerning the benefit of a possible treatment for this condition.

It is now well documented that treatment with anticonvulsant drugs may lead to an osteomalacic state which in the overwhelming majority of cases is very mild. ${ }^{2-4}$ You rightly point out that the catabolic rate of vitamin $D$ is increased in this condition. It is probably noteworthy that the bone mineral content (BMC) decreases slightly (to about $90 \%$ of normal) in the course of a few months and hereafter is kept constant over many years, ${ }^{5}$ 
well in accordance with fundamental pharmacokinetic principles. Naturally the increase of the fractional catabolic rate of the vitamin D metabolites shows a biological variation. It is tempting to assume that overt bone disease in epileptics on anticonvulsants occurs only from the combined effect of a high fractional catabolic rate and low availability of vitamin $\mathrm{D}$, be it due to dietary habits, drug schedules, or minimal exposure to sunlight.

The fact remains that overt bone disease from anticonvulsants alone is very uncommon. It is a truism that patients with overt bone disease should be treated. The crucial point, however, is to diagnose this condition in patients not seeking medical advice for bone symptoms. This would require enormous screening programmes with methods which cannot be considered optimal, whether including alkaline phosphatase and serum calcium estimations, bone biopsy, or measurement of BMC. Another approach might be a prophylactic vitamin $\mathrm{D}$ treatment of all epileptic patients. This would be costly, not withou danger, and with a most uncertain benefit Actually only a few reports have been published concerning the effect of vitamin D treatment on epileptic patients taking anticonvulsants. ${ }^{2-4}$ These reports indicate that BMC can be restored to normal by four months' initial treatment with $4000 \mathrm{IU}$ of vitamin $\mathrm{D}_{2}$ followed by maintenance treatment with $1000 \mathrm{IU}$ daily, but the two published reports on the clinical effect are not too promising. ${ }^{6}$ ?

In conclusion we agree with your statement that "any prophylactic programme which leads to the prescribing of relatively large doses of vitamin $D$ needs to be viewed with circumspection and must be based firmly upon clinical and not simply biochemical benefit" but should like to add that presen available data are more in favour of withholding such prophylactic treatment than giving it.

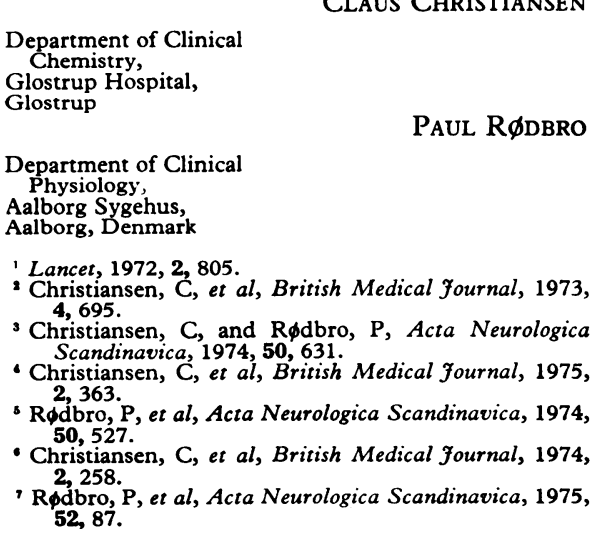

\section{Misuse of statistical methods}

SIR,-The article by Miss Sheila M Gore and her two colleagues ( 8 January, p 85) is very helpful to doctors. In the paragraph on "Disregard for statistical independence" it would have been useful if Miss Gore and her colleagues had indicated how data of this type can be dealt with. I have myself accumulated data on two groups of patients, assigned randomly to two treatment groups, where one has multiple observations from each patient at discrete time intervals. Should data such as these be left in the raw form merely for inspection or are there suitable statistical models for dealing with them?

In their appendix Miss Gore and her colleagues deal with erroneous use of the $\chi^{2}$ test and illustrate the need for using the continuity correction where the numbers are small. In the example they give an uncorrected $\chi^{2}$ with one degree of freedom of 4.5 is reduced to 3.1 when the continuity correction is applied. They are presumably making the assumption that a two-tailed test is appropriate in this situation. However, had a medical investigator who obtained the data with drug $A$ and drug $B$ been advised by a statistician to use a one-tailed criterion of significance on the basis that a new drug $B$ was of interest only if superior to the older drug $A$ the results could have been judged statistically significant. For example, Fisher's exact test for that particular four-fold table, and the three more extreme four-fold tables formed progressively by reducing one of the cell numbers to 0 gives $P=0.0396$, which would be judged just significant. BuchananWollaston's ${ }^{1} \mathrm{Q}$ test on the same data gives $P=0.04$, again showing statistical significance.

If the investigator had been advised to consider a two-tailed possibility-namely, that either drug A or drug B could be superior -and the medical statistician had advocated the use of the logistic transform ${ }^{2}$ on the same data-that is, 7 out of 15 recovery with drug $A$ and 14 out of 17 recovery with drug $B$ -we obtain a two-sided standardised norma deviate of 2.01 significant at the $5 \%$ level.

The investigator should not depend too much on statistical significance but consider taking a few more subjects in the investigation to see whether significant differences tend to increase or decrease and, moreover, consider practical or clinical significance. One recovery with a new treatment in a hitherto untreatable disease may be significant enough.

\section{Chiltern Wing,}

Sutton Hospital

Sutton, Surrey

'Buchanan-Wollaston, H J, On Statistical Treatmen of the Results of Parallel Trials, Freshwater Bio-
logical Association Publication No 10, p 40. Ambleside, FBA, 1945 .
Cox, D R, Analysis of Binary Data, p 35. London, Methuen, 1970 .

SIR,-Miss Sheila Gore and her colleagues (8 January, p 85) may have committed the sort of error they are cautioning doctors against. They find a good fit between observed number of error categories per paper and what would be expected if error categories were distributed randomly according to a Poisson process. This is not a result one would wish to quarrel with, but it does have very strange implications. If authors could be divided into those who use statistics well and those who don't, one would not expect a Poisson process to be an appropriate model for error category distribution.

If error categories do occur randomly throughout papers as the authors suggest, it does not follow that they would continue to do so if the authors' advice to consult medical statisticians were gradually adopted. Papers in the $B M \mathcal{F}$ would then fall into two distinct groups: those written by doctors consulting statisticians and those written by doctors continuing as before. The overal distribution of error categories would no longer be described by a single Poisson process and a quartering of the overall occurrence rate would not, as Miss Gore and her colleagues have calculated, mean that only one paper in 62 would include two or more errors.

\section{STEPHEN SENN}

Tunbridge Wells Health District,

Tunbridge Wells, Kent

\section{Fractures of the tibia}

SIR,-There are always difficulties in describing specialist treatment to a non-specialist audience, but the very fact that the audience is general makes it of extreme importance not to mislead. There are therefore several points in Mr J E M Smith's article on fractures of the tibia (15 January, p 152) with which I should like to take issue.

$\mathrm{Mr}$ Smith states that the Hicks plate can often be left in place after the fracture has healed. This is a dangerous policy to advocate. The Hicks plate is purposely large and strong and therefore stiff. It is a basic engineering principle that stiess travels through the stiffest member in a system. The majority of the stress coming down through the tibia therefore enters the upper end of the plate, passes down through the plate, and re-enters the bone at the lower end of the plate. Stress is thus concentrated at the upper and lower ends of the plate and the bone between is essentially defunctioned. Double plating exacerbates the problem and indeed may result in the bone changing its character from cortical to cancellous. The presence of the plate predisposes to fracture through the first and last screw holes. I have managed to collect several such cases over a relatively short period of time. A very rigid plate should be removed after about one year.

$\mathrm{Mr}$ Smith's dismissal of external skeletal fixation is unwarranted. This method has been popular in Canada for many years. Rather than incorporating the pins in plaster, the pins may be clamped to side bars simply, using the well-tried Roger Anderson apparatus. This gives complete control of the fracture while allowing easy access to the skin. This apparatus has to some extent been superseded by the Wagner leg lengthening and the Hoffman equipment but still remains a simple, cheap, and useful method for treating compound, comminuted, and segmental fractures. The suggestion of the use of a small non-rigid plate as the initial treatment of an irreducible segment with bruised skin is certainly novel, if somewhat lacking in logic. It is in this situation that external skeletal fixation should be used. Furthermore, there is now a substantial school which believes that the Wagner apparatus is the treatment of choice for infected non-union when large segments of infected bone have to be excised and grafted.

Hugh U CAMERON

Department of Orthopaedics,

The London Hospital, London E1

SIR,-Mr J E M Smith's article (15 January, p 152) lacked reference to what is often a very important aspect of this problem-namely, the loss of skin and soft tissue with exposed bone at a fracture site. The patients involved are often young and otherwise fit men for whom an early return to work with a healed fracture and sound skin cover should always be the goal. 